\title{
O-Linked Carbohydrate of Recombinant von Willebrand Factor Influences Ristocetin-induced Binding to Platelet Glycoprotein 1b
}

\author{
Josephine A. Carew, * Suzanne M. Quinn, John H. Stoddart, * and Dennis C. Lynch* \\ Laboratory of Neoplastic Disease Mechanisms, Dana-Farber Cancer Institute, Boston, Massachusetts 02115; \\ and ${ }^{*}$ Departments of Pathology and ${ }^{\ddagger}$ Medicine, Harvard Medical School, Boston, Massachusetts 02115
}

\begin{abstract}
By transfecting the full-length cDNA for human von Willebrand factor ( $v W f$ ) into a line of Chinese hamster ovary cells with a defect in carbohydrate metabolism, we have prepared recombinant $\mathbf{v W f}$ specifically lacking $O$-linked carbohydrates. We have compared this under-glycosylated protein to fully glycosylated recombinant $\mathrm{vWf}$ with respect to several structural and binding properties. vWf deficient in O-linked glycans was synthesized, assembled into multimers, and secreted in an apparently normal manner and was not prone to degradation in the extracellular milieu. It did not differ from fully glycosylated vWf in ability to bind to heparin or to collagen type I but did interact less well with glycoprotein $1 \mathrm{~b}$ on formalin-fixed platelets. This decreased interaction was evidenced in both a lessened overall binding to platelets and in diminished capacity to promote platelet agglutination, in the presence of ristocetin. In contrast, no difference was seen in platelet binding in the presence of botrocetin. These data indicate a possible role for 0 linked carbohydrates in the vWf-glycoprotein $1 \mathrm{~b}$ interaction promoted by ristocetin and suggest that abnormalities in carbohydrate modification might contribute to the altered ristocetindependent reactivity between $\mathrm{vWf}$ and platelets described for some variant forms of von Willebrand disease. (J. Clin. Invest. 1992. 90:2258-2267.) Key words: Chinese hamster ovary cells - glycosylation • protein binding • platelet agglutination • endothelium
\end{abstract}

\section{Introduction}

von Willebrand factor (vWf) ${ }^{1}$ is a large adhesive glycoprotein synthesized by endothelial cells and megakaryocytes, which is found in endothelial cells, platelets, plasma, and the subendothelial matrix as an array of high molecular weight multimers. There are two critical biological functions of vWf. First, it binds noncovalently to and stabilizes clotting Factor VIIIC, the protein that is defective or lacking in hemophilia A. Second, vWf, through its ability to bind strongly to components in the subendothelium and to surface receptors on platelets, initiates plate-

Portions of this work were presented at the meeting of the American Heart Association, Dallas, TX, 11-15 November 1990 (1990. Arteriosclerosis. 10:A904 [Abstr.]) and at the Thirteenth Congress of the International Society on Thrombosis and Haemostasis, Amsterdam, 30 June-6 July 1991 (1991. Thomb. Haemostasis. 65:539 [Abstr.]).

Address correspondence to Josephine A. Carew, Ph.D., Laboratory of Neoplastic Disease Mechanisms, Dana-Farber Cancer Institute, 44 Binney Street, Boston, MA 02115.

Received for publication 11 November 1991 and in revised form 1 July 1992.

J. Clin. Invest.

(c) The American Society for Clinical Investigation, Inc.

$0021-9738 / 92 / 12 / 2258 / 10 \quad \$ 2.00$

Volume 90, December 1992, 2258-2267 let plug formation at the site of an injury to the blood vessel wall (for review see reference 1). Quantitative or qualitative defects in the vWf protein result in a form of the prevalent human bleeding disorder, von Willebrand disease $(\mathrm{vWd})$ (for review see reference 2 ).

In the endothelial cell, vWf is synthesized as a pre-pro-protein in the rough endoplasmic reticulum, where it undergoes core $\mathrm{N}$-glycosylation and forms dimers through disulfide bond formation within the $\mathrm{COOH}$-terminal regions of pairs of provWf subunits ( 3 ). These prodimers are subsequently transported to the Golgi apparatus, where N-linked carbohydrates are processed and sulfated and O-linked carbohydrates are added to each subunit $(4,5)$. The prodimers are then assembled, via disulfide bonds within the $\mathrm{NH}_{2}$-terminal regions of the mature subunits, into a population of multimers containing up to 50 individual vWf subunits (6-8). Although the 741amino acid propeptide of $\mathrm{vWf}$ is required for multimerization, it is not necessary for the functioning of $\mathrm{vWf}$ multimers and generally is cleaved from the 2,050 -amino acid mature subunit $(9,10)$. Noncovalently bound dimers of vWf propeptide circulate in plasma; their biological functions are presently unknown $(11,12)$.

The N-terminal region of the mature vWf subunit is not only involved in multimerization but also contains several binding sites essential to the normal physiological functioning of vWf. Within the initial 728 amino acids of the mature subunit are the binding sites for Factor VIIIC, for the extracellular matrix components heparin and collagen type I, and for the platelet glycoprotein $1 \mathrm{~b}$ (GP 1b) (13-16). vWf must interact strongly with components of the subendothelium and with the platelet surface to mediate platelet attachment and spreading and subsequently to maintain a platelet plug under the high shear stress created by flowing blood. Therefore, an abnormality in the binding between $\mathrm{vWf}$ and one of these components (whether due to the vWf itself or to the other protein) might result in a bleeding disorder. This is the case, for example, in Bernard-Soulier syndrome, where GP $1 \mathrm{~b}$ is absent (17) and therefore the initial interaction between $\mathrm{vWf}$ and platelets cannot occur. It has also been shown that $\mathrm{vWf}$ of patients with type IIB vWd can bind spontaneously to platelets, with consequent depletion of both circulating platelets and of the larger, more reactive multimers of plasma $\mathrm{vWf}$ (18).

The structural determinants of vWf participating in the interactions with platelet GP $1 \mathrm{~b}$ and extracellular matrix components are therefore of great interest. Recently, several aspects of the binding sites within the region comprised by amino acids 449-728 of the mature subunit of vWf have been further delin-

1. Abbreviations used in this paper: EC, endothelial cells; Gal, galactose; GalNAc, $N$-acetyl-glactosamine; G-418, geneticin sulfate; GP $1 \mathrm{~b}$, glycoprotein $\mathrm{lb} ; \mathrm{O}^{+}$, containing O-glycans; $\mathrm{O}^{-}$, lacking O-glycans; TBS, Tris-buffered saline; vWd, von Willebrand disease; vWf, von Willebrand factor. 


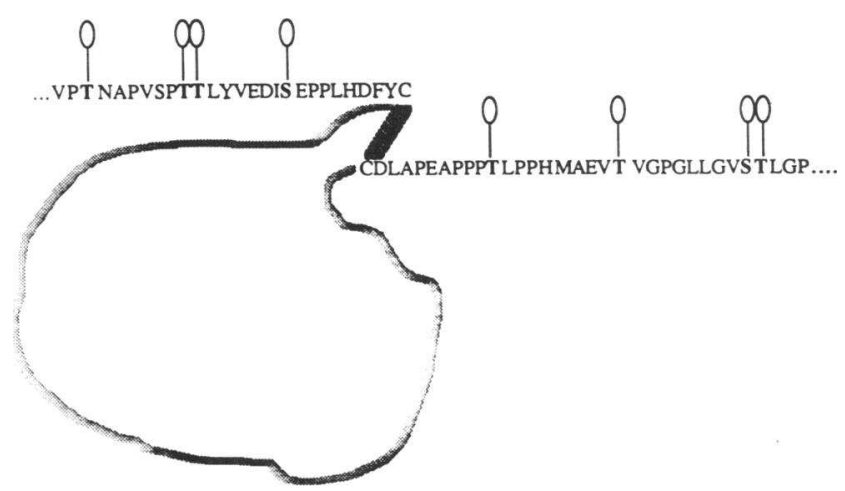

Figure 1. Schematic depiction of the platelet GP $1 \mathrm{~b}$-binding region of $\mathrm{vWf}$. The region of the $\mathrm{vWf}$ mature subunit from amino acid 483 to amino acid 727 is schematically represented, with the actual sequences from residues $483-509$ and $695-727$ given. The residues that undergo O-linked glycosylation ( Thr residues 485, 492, 493, 705, 714 , and 724 and Ser residues 500 and 723) are shown in boldface type with open symbols above. The intrachain disulfide bond between Cys residues 509 and 695 (48) draws into close spatial proximity the regions of the $\mathrm{vWf}$ primary sequence that participate in the ristocetin-induced interaction with platelet GP $1 \mathrm{~b}(19)$.

eated. Synthetic peptides spanning the sequences of two noncontiguous regions of vWf (residues 469-498 and 689-713) have been shown to synergistically inhibit the ristocetin-dependent binding between native $\mathrm{vWf}$ and GP $\mathrm{lb}$. The greatest inhibition was exhibited by individual peptides corresponding to vWf sequences between amino acid residues 474-488 and 694-708 (19). Because there is a disulfide bond between Cys residues 509 and 695 (see Fig. 1), these regions are brought into close proximity in the native vWf protein $(19,20)$. However, the same peptides do not block botrocetin-induced binding between GP $1 \mathrm{~b}$ and $\mathrm{vWf}(21)$. In contrast, proteolytic fragments of vWf containing amino acids 512-673 (that is, residues within the loop created by the Cys 509-Cys 695 disulfide bond) inhibit binding between native $\mathrm{vWf}$ and both heparin and collagen type I, whereas proteolytic fragments of vWf lacking this region do not (22), suggesting that determinants within this area are necessary for the interactions between $\mathrm{vWf}$ and these matrix constituents. This disulfide loop region is also required for binding between $\mathrm{vWf}$ and GP $1 \mathrm{~b}$ in the presence of botrocetin, but not ristocetin (23).

The mature subunit of $\mathrm{vWf}$ is glycosylated, bearing $12 \mathrm{~N}$ linked carbohydrates and 10 O-linked carbohydrates (4). 8 of the 10 O-linked glycans are located within or near the noncontiguous regions that are required for ristocetin-induced binding between vWf and GP $1 \mathrm{~b}$ (Fig. 1), and indeed, two of these O-glycans, at Thr residues 485 and 705 , occur within the two peptides found to be most efficient in inhibition of ristocetininduced binding (19). This marked clustering of O-linked glycosylation sites suggested that these modifications might influence the interaction between $\mathrm{vWf}$ and platelets that leads to the formation of a platelet plug.

Whether the O-linked glycans play any role in this or in any other function of vWf is not presently known. To assess the possible influence of O-glycans upon the properties of $\mathrm{vWf}$, we constructed a vector containing the full-length cDNA for human vWf and transfected it into a mutant line of Chinese hamster ovary cells that exhibit a severe but reversible defect in carbohydrate metabolism. In this way, fully glycosylated recombinant $\mathrm{vWf}$ and recombinant $\mathrm{vWf}$ with intact $\mathrm{N}$-linked carbohydrates but devoid of O-linked carbohydrates have been produced. We have employed these to investigate the participation of O-glycans in binding of vWf to several ligands. We report here that $\mathrm{vWf}$ lacking $\mathrm{O}$-linked carbohydrate modifications bound normally to heparin and to collagen, and to platelets in the presence of botrocetin, but that it exhibited reduced binding to GP $1 \mathrm{~b}$ and limited ability to agglutinate platelets in the presence of moderate amounts of ristocetin.

\section{Methods}

\section{Materials}

ldl-D cells were generously provided to us by Dr. M. Krieger (Massachusetts Institute of Technology, Cambridge, MA). pvW-198 was constructed by inserting the full-length cDNA for vWf into p-198 (a gift of N. Sarver, National Institutes of Health, Bethesda, MD) such that its expression is under the control of the cytomegalovirus enhancer and the SV40 immediate-early promoter; this plasmid also contains the SV40 terminator. pHSV-neo (a gift of D. Kaplan and T. Roberts, DanaFarber Cancer Institute, Boston, MA) contains the bacterial neomycin-resistance gene under the control of the Harvey sarcoma virus LTR and is analogous to $\mathrm{pSV}_{2}$-neo (24). Polyclonal rabbit anti-human vWf antibody, monoclonal antihuman GP $1 \mathrm{~b}$ antibody, horseradish-peroxidase-conjugated polyclonal rabbit anti-human vWf antibody, and orthophenylenediamine were products of DAKO Corporation (Dakopatts, Copenhagen, Denmark), as was the alkaline-phosphataseconjugated goat anti-rabbit polyclonal antibody. Monoclonal antibody to an epitope in the $\mathrm{COOH}$ terminus of the mature vWf subunit (2.2.9) covalently coupled to Sepharose was a gift of Dr. Z. Ruggeri (La Jolla, CA). Normal pooled human plasma was obtained from George King Bio-Medical, Inc. (Overland Park, KS). Radioisotopes were purchased from DuPont New England Nuclear (Boston, MA). Chemical reagents, including galactose ( $\mathrm{Gal})$ and $N$-acetyl-galactosamine ( $\mathrm{Gal}$ NAc), were from Sigma Chemical Co. (St. Louis, MO), as were uncoupled Sepharose beads. Type I bovine collagen was from Worthington Biochemical Corp. (Freehold, NJ). Materials for agarose gel electrophoresis were obtained from FMC Corp. (Rockland, ME) whereas those for polyacrylamide gel electrophoresis were from Bio-Rad Laboratories (Rockville Center, NY). The media for metabolic labeling experiments were prepared from the Gibco minimal essential medium Select-Amine Kit, supplemented with Gal and/or GalNAc as noted; growth media, antibiotics, geneticin sulfate (G-418), and serum were also obtained from Gibco Laboratories (Grand Island, NY). ITS+ serum supplement was obtained from Collaborative Research (Bedford, MA). Botrocetin was the generous gift of Dr. Marjorie Read (University of North Carolina, Chapel Hill, NC). Formalin-fixed human platelets and ristocetin were purchased from Bio-Data Corp. (Hatboro, PA), and heparin-Sepharose beads were purchased from Pharmacia LKB Biotechnology Inc. (Uppsala, Sweden ). Microconcentration units $(100,000 \mathrm{~mol}$ wt cutoff) were purchased from Amicon (Beverly, MA) and microtiter plates were purchased from Flow Laboratories, Inc., subsid. of Flow General Inc. (McLean, VA). A transfer apparatus (Transphor; Hoefer Scientific Instruments, San Francisco, CA) and nitrocellulose paper (Nitroscreen West; DuPont New England Nuclear) were used for Western blotting. 5-Bromo-4-chloro-3-indolyl-phos- 
phate (BCIP) and nitro blue tetrazolium (NBT) were purchased from Promega Corp. (Madison, WI).

\section{Cell culture}

Stock ldl-D cells were maintained in Ham's F12 medium supplemented with $2 \mathrm{mM}$ glutamine, $100 \mathrm{U} / \mathrm{ml}$ penicillin, 100 $\mu \mathrm{g} / \mathrm{ml}$ streptomycin, and $5 \%$ fetal bovine serum, at $37^{\circ} \mathrm{C}$ in a humidified $5 \% \mathrm{CO}_{2}: 95 \%$ air incubator. After stable transfection, cells were cultured in the same medium containing 125 $\mu \mathrm{g} / \mathrm{ml} \mathrm{G}-418$. Normal human umbilical vein endothelial cells (EC), elaborating native vWf were used as a positive control in some experiments and were cultured as previously described (6).

To produce vWf with altered carbohydrate modifications, clone A-16 cells ( an isolate of ldl-D cells stably transfected with pvW-198 and pHSV-neo) were trypsinized on day 0 into fullgrowth medium. On day 1 , the medium was replaced with one of two Ham's/ITS+ selective media. Ham's/ITS+ is Ham's F12 medium supplemented with penicillin and streptomycin and, in place of serum, a mixture of the following: insulin $(0.625 \mathrm{mg} / \mathrm{ml})$, transferrin $(0.625 \mathrm{mg} / \mathrm{ml})$, selenium $(0.625$ $\mu \mathrm{g} / \mathrm{ml})$, linoleic acid $(0.535 \mathrm{mg} / \mathrm{ml})$, and bovine serum albu$\min (0.125 \mathrm{mg} / \mathrm{ml})$. This formulation was supplemented either with $20 \mu \mathrm{M} \mathrm{Gal}$ (glycoproteins will be deficient in Olinked glycans only) or with $200 \mu \mathrm{M} \mathrm{GalNAc}$ and $20 \mu \mathrm{M} \mathrm{Gal}$ (glycoproteins will contain O-linked as well as $\mathrm{N}$-linked glycans). Therefore these selective media are referred to respectively as $\mathrm{O}^{-}$and $\mathrm{O}^{+}$media. A- 16 cells were preincubated for 48 $\mathrm{h}$ in the selective media to deplete their internal sugar nucleotide pools of GalNAc if necessary. For collection of conditioned medium samples, fresh Ham's/ITS+ selective media or labeling media were then applied.

\section{Transfection}

Stock ldl-D cells were seeded into growth medium at 750,000 cells per $100-\mathrm{mm}$ dish and were treated at $37^{\circ} \mathrm{C}$ for $5.5 \mathrm{~h}$ either with a calcium phosphate-DNA precipitate containing $40 \mu \mathrm{g}$ of pvW-198 and $10 \mu \mathrm{g}$ of pHSV-neo DNAs or with a mock transfection mixture containing a calcium phosphate precipitate but no DNA. Cells were washed with PBS and fed with full-growth medium immediately, and again at $24 \mathrm{~h}$ after transfection. At $48 \mathrm{~h}$ the cells were trypsinized to new dishes and placed in growth medium containing $250 \mu \mathrm{g} / \mathrm{ml}$ of G-418. Transfected colonies resistant to G-418 were isolated, expanded, and assessed for expression of vWf by ELISA. A-16 is a G-418-resistant isolate expressing vWf; A-42 is a G-418-resistant isolate that does not elaborate $\mathrm{vWf}$ protein. No ldl-D cells survived on dishes that underwent mock transfection.

\section{ELISA for $v W f$}

The sandwich ELISA employed in this work was performed as follows. A rabbit polyclonal anti-human vWf antibody was applied to the wells of a microtiter dish, and then samples were added and allowed to bind the antibody. Next, a second polyclonal anti-human vWf antibody, conjugated to horseradish peroxidase, was applied. The wells were incubated with the substrates orthophenylenediamine and hydrogen peroxide. After development of colored product, the enzyme reaction was quenched by addition of sulfuric acid, and the optical density of the solution in each well was determined using a microplate reader (Titer-Tek Multiscan Plus; Flow Laboratories, Inc., subsid. of Flow General Inc.). As a vWf standard, pooled normal human plasma was used.

\section{Metabolic labeling and immunoprecipitation}

After preincubation in $\mathrm{O}^{-}$or $\mathrm{O}^{+}$Ham's/ITS+ media for $48 \mathrm{~h}$, A-16 or A-42 cells were labeled in serum-free MEM supplemented with $20 \mu \mathrm{M} \mathrm{Gal}\left(\mathrm{O}^{-}\right.$-labeling medium) or with $200 \mu \mathrm{M}$ GalNAc and $20 \mu \mathrm{M} \mathrm{Gal}\left(\mathrm{O}^{+}\right.$-labeling medium) and [ $\left.{ }^{35} \mathrm{~S}\right]-$ cysteine at the specific activities noted. Conditioned media were collected, and the vWf was immunoprecipitated and electrophoresed on SDS-polyacrylamide or SDS-agarose gels as described previously (5). For some experiments, the polyclonal antibody employed in the ELISA assay was employed for immunoprecipitation whereas for other experiments, the monoclonal antibody 2.2 .9 , covalently coupled to Sepharose, or a mixture of these, was employed. A-42 and EC were similarly treated.

\section{Binding assays}

The media of A-16 cells were collected for $48 \mathrm{~h}$ as described and was concentrated 10 -fold. vWf protein levels were determined by ELISA so that equivalent amounts of each were employed. Typical $\mathrm{vWf}$ levels were between 0.5 and $1 \mu \mathrm{g} / \mathrm{ml}$.

Heparin binding. Aliquots of concentrated $\mathrm{O}^{-}$or $\mathrm{O}^{+}$collection media were incubated with Sepharose beads containing or lacking immobilized heparin, in $50 \mathrm{mM}$ Tris-buffered saline (TBS) pH 7.4 containing 1\% BSA (TBS-BSA), for $30 \mathrm{~min}$ with rocking, at room temperature (14). The unbound supernatant was removed, and the beads were washed and then eluted with TBS-BSA containing concentrations of $\mathrm{NaCl}$ $\leq 0.5 \mathrm{M}$. All fractions were then assayed by ELISA.

Collagen binding. Collagen binding was assayed by a modification of the procedure of Bockenstedt et al. (25). An 11 $\mathrm{mg} / \mathrm{ml}$ bovine type I acid-soluble collagen stock solution was diluted to $1.87 \mathrm{mg} / \mathrm{ml}$ in $20 \mathrm{mM}$ sodium citrate buffer $\mathrm{pH} 6.1$. This solution was used to coat the wells of a microtiter plate for $90 \mathrm{~min}$ at $37^{\circ} \mathrm{C}$. Subsequently the wells were washed with 50 $\mathrm{mM}$ Tris buffer $\mathrm{pH} 7.4$ plus $150 \mathrm{mM} \mathrm{NaCl}$ and were blocked with $0.1 \% \mathrm{BSA}$ in that buffer for $60 \mathrm{~min}$ at room temperature. Dilutions of conditioned media containing $\mathrm{O}^{-}$or $\mathrm{O}^{+}$recombinant $\mathrm{vWf}$ were then added to the wells and the level of $\mathrm{vWf}$ bound to the collagen after a $60-\mathrm{min}$ incubation at $37^{\circ} \mathrm{C}$ was determined with the rabbit anti-human vWf polyclonal antibody conjugated to horseradish peroxidase, as described for the ELISA assay.

$G P 1 b$ binding. To assay ristocetin-dependent binding of $\mathrm{vWf}$ to platelets, aliquots of $\mathrm{O}^{-}$or $\mathrm{O}^{+}$collection media were incubated in TBS with Formalin-fixed human platelets in TBS at $1 \times 10^{8} / \mathrm{ml}$, final concentration in $400 \mu \mathrm{l}$ total volume. Ristocetin was added to the final concentrations noted. After rocking at room temperature for $30 \mathrm{~min}$, the platelets were sedimented by centrifugation, and the levels of vWf remaining in the supernatant were determined by ELISA. No spontaneous binding to platelets in the absence of ristocetin occurred with either sample. Assays with botrocetin were performed in a similar manner.

Platelet agglutination. $\mathrm{O}^{-}$or $\mathrm{O}^{+}$culture media were concentrated as described above, and then aliquots of these samples were stirred at $37^{\circ} \mathrm{C}$, along with Formalin-fixed human platelets at $1 \times 10^{8} / \mathrm{ml}$, in a total volume of $400 \mu \mathrm{l}$, in cuvettes of a dual-channel aggregometer (Sienco, Inc., Morrison, CO). The change in light transmittance through each sample was monitored after addition of ristocetin at the concentrations noted. 


\section{Western blotting}

After electrophoresis, $\mathrm{vWf}$ protein from SDS-agarose gels was blotted to nitrocellulose paper by a 5 - $h$ transfer at $0.5 \mathrm{~mA}$ in 20 $\mathrm{mM}$ Tris, $150 \mathrm{mM}$ glycine buffer $\mathrm{pH} 8.3$ containing $20 \%$ ( vol/ vol) methanol and $0.01 \%$ SDS in a transfer apparatus (Transphor; Hoefer Scientific Instruments). The blot was blocked in a solution of $5 \%$ Carnation ${ }^{\circledR}$ dry milk in PBS, and then incubated with anti-vWf polyclonal antibody at $1: 500(\mathrm{vol} / \mathrm{vol})$ in $10 \mathrm{mM}$ Tris buffer $\mathrm{pH} 7.4$ containing $150 \mathrm{mM} \mathrm{NaCl}$ and $4 \%$ BSA (wt/vol). After washing, the blot was incubated with detecting antibody (alkaline-phosphatase-conjugated goat antirabbit polyclonal antibody) and then developed with the colorimetric phosphatase substrates nitro blue tetrazolium and 5bromo-4-chloro-3-indolyl-phosphate.

\section{Results}

Characteristics of ldl-D cells. Idl-D cells are a Chinese hamster ovary line that are severely deficient in UDP-galactose 4-epimerase and UDP- $N$-acetyl-galactosamine 4-epimerase activities (26). Since these cells cannot interconvert UDP-glucose and UDP-galactose (UDP-Gal), or UDP- $N$-acetyl-glucosamine and UDP- $N$-acetyl-galactosamine (UDP-GalNAc), they consequently cannot incorporate either Gal or GalNAc into carbohydrate chains when provided with medium lacking these sugars. However, when Gal and/or GalNAc are provided in the culture medium, ldl-D cells take them up and convert them to UDP-Gal and UDP-GalNAc by salvage pathways. Because GalNAc is only rarely found in N-linked glycans but is the initial residue of the mucin-type O-linked carbohydrate chains added to glycoproteins in the Golgi apparatus of animal cells (27), the omission of GalNAc from the culture medium permits selective suppression of O-linked glycosylation. $\mathrm{Gal}$ is a common constituent of both $\mathrm{N}$-linked and O-linked glycans, therefore its inclusion in the culture medium when GalNAc is absent insures that $\mathrm{N}$-linked carbohydrates will be processed normally. When both Gal and GalNAc supplement the culture medium, the synthesis of both the $\mathrm{N}$-linked and O-linked carbohydrate chains of glycoproteins is unimpeded.

Subunit structure, multimer assembly, secretion, and stability of $v W f$. A cytomegalovirus-based expression vector containing the full cDNA for human vWf was transfected into ldl-D cells and those clones expressing vWf, as detected by ELISA, were isolated as described in Methods. One isolate, referred to as A-16, has been employed for the experiments reported in this paper. On a per cell basis, A- 16 cells express approximately the same level of $\mathrm{vWf}$ protein as do human umbilical vein EC (data not shown). In some experiments, another isolate of ldlD cells, termed A-42, which does not express vWf, has been used as a negative control.

After a 48-h preincubation in $\mathrm{O}^{-}$or $\mathrm{O}^{+}$media, A-16 cells were labeled for $16 \mathrm{~h}$ with $\left[{ }^{35} \mathrm{~S}\right]$ cysteine. Their culture media were then immunoprecipitated with a mixture of a monoclonal antibody directed against an epitope in the $\mathrm{COOH}$-terminal portion of the vWf mature subunit and a polyclonal anti-vWf antibody. The culture conditions influenced the electrophoretic mobilities of the vWf large and mature subunits, as can be seen in Fig. 2. When devoid of O-linked glycans, the large and mature subunits of vWf exhibited a greater electrophoretic mobility than did the completely glycosylated subunits. Because most of the $\mathrm{vWf}$ recovered from conditioned medium was in

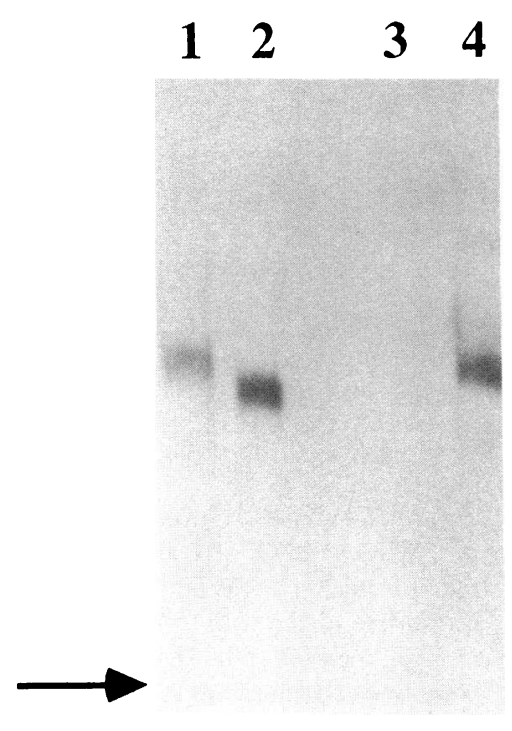

Figure 2. Expression of vWf in A-16 cells. A-16 cells in serum-free $\mathrm{O}^{+}$ (lane 1 ) or $\mathrm{O}^{-}$(lane 2) media were labeled for $16 \mathrm{~h}$ with $\left[{ }^{35} \mathrm{~S}\right]$ cysteine at $50 \mu \mathrm{Ci} / \mathrm{ml}$. Confluent A-42 cells, ldl-D cells that do not express recombinant vWf (lane $3)$, and human umbilical vein EC (lane 4) were labeled under identical conditions in the $\mathrm{O}^{-}$medium. The labeled conditioned media from these cultures were immunoprecipitated with a mixture of polyclonal anti-vWf antibody and anti-vWf

monoclonal antibody 2.2 .9 , and then analyzed on a $6 \%$ denaturing polyacrylamide gel, as described. The arrow shows the migration position of a $180-\mathrm{kD}$ marker protein. The exposure period was $1 \mathrm{~d}$.

the form of the mature subunit, proteolytic processing to remove the propeptide of recombinant pro-vWf must occur before secretion. The fully glycosylated vWf, synthesized by A-16 cells in the presence of both Gal and GalNAc, was indistinguishable in electrophoretic mobility from that synthesized by human umbilical vein EC. As expected, no labeled material was detected in the control lane, containing immunoprecipitate of the conditioned medium from the non-vWf-expressing A-42 cells.

The $\left[{ }^{35} \mathrm{~S}\right]$ cysteine-labeled samples from a similar experiment were analyzed on a discontinuous $1.5 \%$ SDS-agarose gel (Fig. 3). A Western blot of this gel was done, and the multimer pattern of normal pooled human plasma, which was not immunoprecipitated before application to the gel, is shown in lane 1 . Lanes 2 and 3 are the autoradiographs of immunoprecipitated samples of recombinant vWf with and without Olinked glycans, respectively. Both the Western blot and its autoradiograph demonstrate the presence of multimers in recombinant vWf, whether fully glycosylated or deficient in O-glycans.

In this system as well, the difference in electrophoretic mobility of $\mathrm{vWf}$ with altered carbohydrate modifications was observed. The higher molecular weight multimers of $\mathrm{vWf}$ were assembled and secreted under conditions where O-glycosylation was not carried out. Since, unlike human umbilical vein EC, ldl-D cells do not have a regulated secretion pathway, the largest multimers are not as prevalent as those seen in the conditioned medium of EC or in plasma (references 3, 28; Fig. 3). However, multimers up to the 20 -mer are detectable in the conditioned media of the ldl-D cells, regardless of whether Olinked glycans are present. Migrating behind each major band are satellite multimers containing one or more subunits of large $\mathrm{vWf}$. These data indicate that the absence of O-linked glycans does not adversely affect the process of $\mathrm{vWf}$ multimerization.

The data described above demonstrated that $\mathrm{vWf}$ without O-linked glycans was multimerized, processed by proteolytic removal of the propeptide, and constitutively secreted from A-16 cells. A lack of O-glycans interfered with translocation of at least one membrane glycoprotein, the gp 55 of the IL-2 recep- 


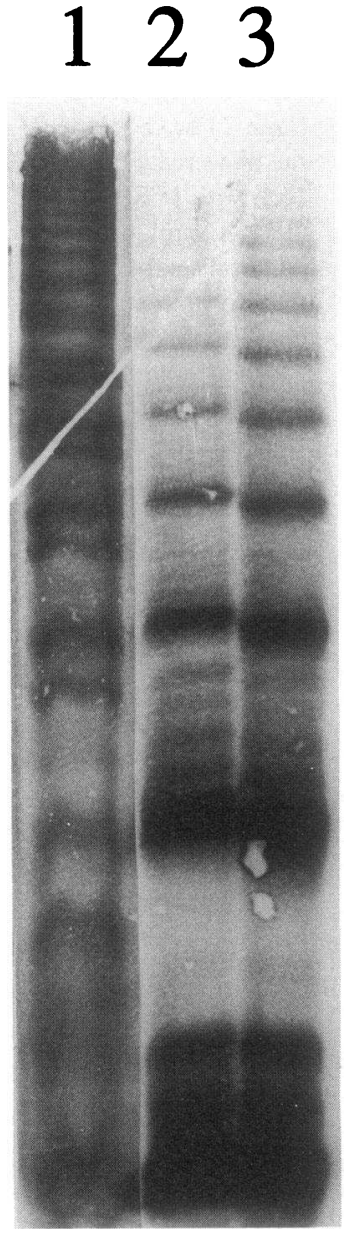

Figure 3. Agarose gel electrophoresis of $\mathrm{vWf} \mathrm{O}^{+}$and $\mathrm{O}^{-} \mathrm{vWf}$ were prepared from A-16 cells labeled in serum-free media with $\left[{ }^{35} \mathrm{~S}\right.$ ] cysteine at $50 \mu \mathrm{Ci} / \mathrm{ml}$ for $16 \mathrm{~h}$. The labeled conditioned media from these cultures were immunoprecipitated with monoclonal anti-vWf antibody, and the vWf multimers were analyzed on a $1.5 \%$ discontinuous SDS-agarose gel, along with $5 \mu$ l of pooled normal human plasma $(\sim 50 \mu \mathrm{g} \mathrm{vWf})$. A Western blot of this gel was then done. Lane 1 corresponds to the vWf of human plasma, photographed from the Western blot. The autoradiograph of the blot is shown in lanes 2 and 3; lane 2 corresponds to $\mathrm{O}^{+}$recombinant $\mathrm{vWf}$ and lane 3 to $\mathrm{O}^{-}$recombinant vWf. The exposure for the autoradiogram was $20 \mathrm{~d}$.

tor (29), however, when the relative rates and extents of $\mathrm{vWf}$ secretion under each condition of carbohydrate modification were examined by pulse-chase experiments, no discernable difference was noted (unpublished data).

The stability of some membrane glycoproteins is compromised by a lack of O-linked carbohydrate $(26,30)$. In contrast, vWf devoid of O-linked carbohydrates did not seem to be markedly unstable relative to its fully glycosylated counterpart. During shorter term experiments, such as labeling periods of 16 to $24 \mathrm{~h}$, there was clearly accumulation of intact vWf multimers in the conditioned medium (for example, Fig. 3). Also, polyclonal anti-vWf antibody did not immunoprecipitate fragments of vWf detectable on polyacrylamide gels (data not shown). Whether a lack of O-linked glycans affected the longer-term stability of vWf was investigated by incubating labeled conditioned medium from A-16 cells cultured under the various conditions in the presence of growing A- 42 cells for $5 \mathrm{~d}$. Then, the conditioned medium from the A- 42 cultures was immunoprecipitated with polyclonal anti-vWf antibody. These samples were compared on SDS-polyacrylamide gels with aliquots that were immunoprecipitated immediately after the labeling period was completed (Fig. $4 A$ ). When the radioactive label in each band was quantitated using a blot analyzer (Beta Scope; Betagen, Waltham, MA), it was found that nearly equal amounts of radioactivity were present in the vWf bands immunoprecipitated before and after $5 \mathrm{~d}$ of incubation in the presence of the A-42 cells. Samples prepared similarly were immunoprecipitated with monoclonal anti-vWf antibody and analyzed by agarose gel electrophoresis (Fig. $4 \mathrm{~B}$ ). A full range of vWf multimers was recovered from both samples, and no leading satellites were observed in either. Thus, lack of $\mathrm{O}$ linked glycans does not seem to lead to proteolytic instability of $\mathrm{vWf}$ in the tissue culture environment.

Effects of O-glycosylation on $v W f$ binding and platelet agglutination. Since 8 of the 10 O-linked glycosylation sites on the 2,050-amino acid mature vWf subunit are located within the region encompassing the heparin, collagen type $I$, and platelet GP $1 \mathrm{~b}$ binding sites, we investigated whether the O-linked carbohydrates might be functionally important to the binding between $v W f$ and these proteins.

Both vWf with N-linked and O-linked glycans and vWf selectively lacking the O-linked glycans did bind to Sepharose beads that were chemically coupled to heparin (Fig. 5) but not to Sepharose beads alone (data not shown). These vWf samples were eluted from the heparin-Sepharose at the expected $\mathrm{NaCl}$ concentrations $(0.20-0.25 \mathrm{M})(14)$. When assayed for ability to bind to collagen type I, again no discrepancy was seen between vWf samples possessing or lacking O-linked carbohydrates (data not shown).

In contrast, we observed that whereas vWf modified by $\mathrm{O}$ glycans bound to formalin-fixed human platelets at low concentrations of ristocetin, vWf without O-glycans did not (Fig. 6 ). At higher ristocetin concentrations, the inability of the underglycosylated vWf to bind to platelets appeared to be partly overcome, although the observed binding was clearly less than that observed for the fully glycosylated vWf at the same concentration of ristocetin. There was negligible binding of either $\mathrm{vWf}$ sample to the platelets in the absence of ristocetin and negligible reaction between either $\mathrm{vWf}$ sample and ristoctin in the absence of platelets. The interaction between platelets and recombinant $\mathrm{O}^{+} \mathrm{vWf}$ was inhibitable by a monoclonal anti-GP $1 \mathrm{~b}$ antibody, suggesting that binding is via the GP $1 \mathrm{~b}$ receptor (unpublished results). Since equivalent amounts of vWf protein were used, and since the underglycosylated sample is not unstable or of a significantly different multimer distribution than the fully glycosylated sample, the lower binding could be attributed to a diminished interaction between this vWf sample and the platelet GP $1 \mathrm{~b}$. However, we also examined the binding between $\mathrm{O}^{-}$and $\mathrm{O}^{+} \mathrm{vWf}$ and formalin-fixed platelets in the presence of botrocetin and found that this agent promoted the interaction regardless of the glycosylation state of the $\mathrm{vWf}$ (Fig. 7).

To further analyze the interaction between these vWf samples and GP $1 \mathrm{~b}$, we performed agglutination assays of $\mathrm{O}^{-}$and $\mathrm{O}^{+}$-conditioned media containing equivalent amounts of $\mathrm{vWf}$ with formalin-fixed human platelets and ristocetin at several different final concentrations (Fig. 8). The vWf was capable of supporting agglutination of platelets both in the presence and the absence of O-glycans, but again the extent of the reaction was dependent upon the glycosylation state of the vWf. The agglutination was more extensive for $\mathrm{O}^{+} \mathrm{vWf}$ than $\mathrm{O}^{-} \mathrm{vWf}$ at each level of ristocetin. Thus, in terms of ability to support ristocetin-dependent agglutination, the vWf lacking O-linked glycans was also deficient in comparison to the $\mathrm{vWf}$ possessing O-linked glycans.

\section{Discussion}

The contributions of O-linked glycans to the properties of glycoproteins are not well understood. At present, there are two 
B

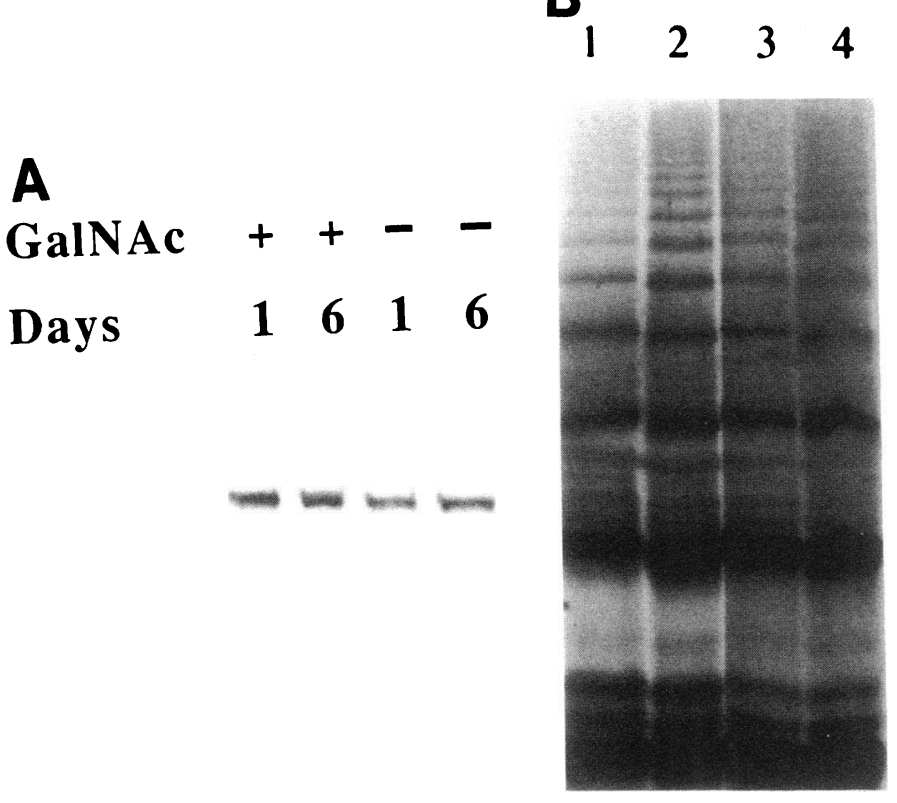

Figure 4. Stability of vWf. $(A)$ A-16 cells were labeled with $\left[{ }^{35} \mathrm{~S}\right]-$ cysteine at $100 \mu \mathrm{Ci} / \mathrm{ml}$ for $18 \mathrm{~h}$ in serum-free $\mathrm{O}^{+}$or $\mathrm{O}^{-}$media. Each sample of conditioned medium was then divided in half. One half of each was immunoprecipitated immediately (day 1 ) with a mixture of polyclonal and monoclonal anti-vWf antibodies. The other half of each was incubated with a growing culture of A-42 cells, ldl-D cells that do not express vWf, for 5 additional days before immunoprecipitation (day 6). These samples were then electrophoresed on an $8 \%$ denaturing polyacrylamide gel. The exposure period was $1 \mathrm{~d}$. The level of $\left[{ }^{35} \mathrm{~S}\right]$ cysteine in each band was determined using a blot analyzer. By this analysis the amount of radioactivity recovered in each day 6 sample was virtually identical to that present in the corresponding day 1 sample. (B) A-16 cells were labeled with [ ${ }^{35} \mathrm{~S}$ ] cysteine at $50 \mu \mathrm{Ci} / \mathrm{ml}$ for $18 \mathrm{~h}$ in serum-free $\mathrm{O}^{+}$ or $\mathrm{O}^{-}$media. These conditioned media samples were treated as described for $A$, except that the monoclonal antibody 2.2 .9 was employed for immunoprecipitation. The samples were then analyzed on a discontinuous $1.5 \%$ SDS-agarose gel. The exposure period was $20 \mathrm{~d}$.

cially useful when the glycosylation pattern is relatively simple. For example, this method has been employed to show that the presence of O-glycans may influence protein conformation. In physical studies of ovine submaxillary mucin, which is very heavily glycosylated by a single disaccharide, $\alpha$-NeuNAc(26) $\alpha$-GalNAc-O-Ser/Thr, it was found that fully glycosylated and asialo mucins assume an extended random coil conformation. Removal of both the sialic acid and the GalNAc, however, caused the mucin peptide backbone to assume a conformation

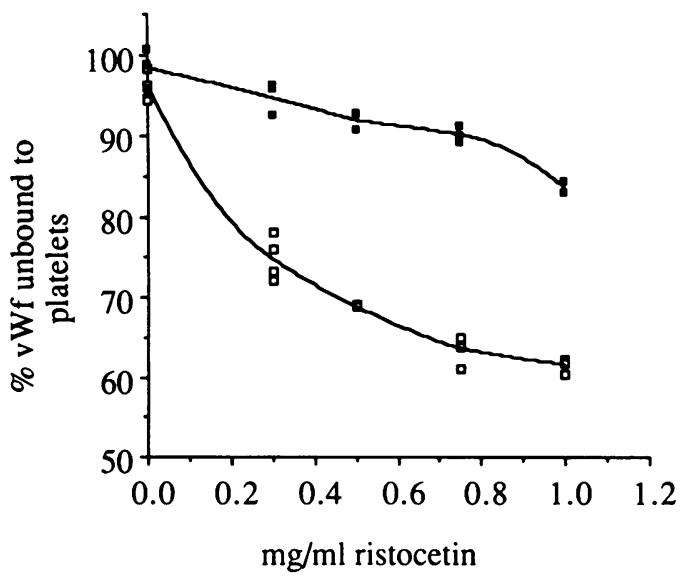

Figure 6. Binding of recombinant $\mathrm{vWf}$ to platelets in the presence of ristocetin. Aliquots of A-16 culture medium collected for $48 \mathrm{~h}$ in $\mathrm{O}^{+}$ or $\mathrm{O}^{-}$serum-free selective media were concentrated 10-fold. Equivalent amounts of $\mathrm{vWf}$ were added to $4 \times 10^{7}$ Formalin-fixed human platelets reconstituted in $50 \mathrm{mM}$ Tris buffer $\mathrm{pH} 7.4$ plus $150 \mathrm{mM}$ $\mathrm{NaCl}$. The indicated concentrations of ristocetin were added, and the reaction mixtures were incubated with rocking at room temperature for $30 \mathrm{~min}$. Then the platelets were sedimented by centrifugation and the levels of $v W f$ remaining in the supernatant were determined by ELISA. The open symbols depict the percent of the initial $\mathrm{O}^{+} \mathrm{vWf}$ level remaining after incubation, whereas the closed symbols depict the percent of the initial $\mathrm{O}^{-} \mathrm{vWf}$ level remaining after incubation. No spontaneous binding to platelets in the absence of ristocetin occurred with either sample. 


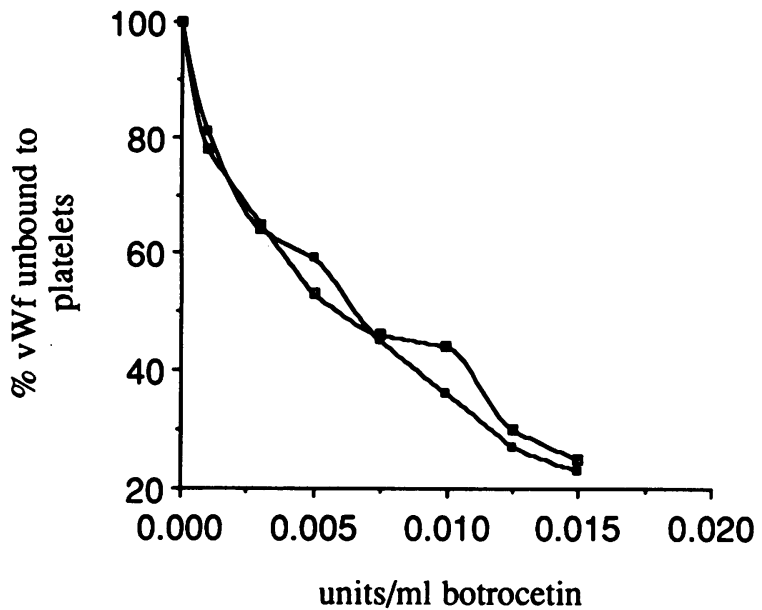

Figure 7. Binding of recombinant vWf to platelets in the presence of botrocetin. Assays were performed as for ristocetin-induced binding, except that the reaction time was $15 \mathrm{~min}$. Again, the open symbols depict the percent of the initial $\mathrm{O}^{+} \mathrm{vWf}$ level remaining after incubation, whereas the closed symbols depict the percent of the initial $\mathrm{O}^{-}$ vWf level remaining after incubation. No spontaneous binding to platelets in the absence of botrocetin was noted.

similar to that of a denatured globular protein (31). The O-glycans, and in particular the initial GalNAc residues, are apparently responsible for maintaining the native structure. Similarly, in a study of recombinant human granulocyte colonystimulating factor, the presence of the single carbohydrate modification, an O-glycan, was found necessary to maintain the native conformation and activity over a period of days (32).

For the study of recombinant glycoproteins with more complex glycosylation patterns, a second experimental system has recently become available. This system uses ldl-D cells, with their bypassable deficiency of UDP-galactose 4-epimerase and UDP- $N$-acetyl-galactosamine 4-epimerase activities. Using this system, it has been demonstrated that although two cell-surface glycoproteins, the low-density lipoprotein receptor (26) and the decay-accelerating factor (30), are normally synthesized and transported, they are unstable in the extracellular milieu and are quickly degraded. Another surface glycoprotein, the gp55 of the IL-2 receptor (29) is apparently transported improperly within the ldl-D cells when not O-glycosylated. In contrast, two soluble glycoproteins, apolipoprotein E (33) and the $\beta$-subunit of human chorionic gonadotropin (34), are not destabilized or incorrectly transported when lacking in O-glycans.

Previous studies of the influence of carbohydrate on the functions of human vWf used enzymatic treatments of the native protein and have shown that deglycosylation can induce both instability to proteases and alterations in adhesiveness. vWf exhibits a complicated pattern of carbohydrate modification, with $12 \mathrm{~N}$-linked glycans and $10 \mathrm{O}$-linked glycans present on each mature subunit. 8 of the 10 O-linked glycans are situated between residues 485-500 and 705-724, short regions of vWf protein backbone that are believed to be close together in the tertiary structure (19), with the other two O-linked glycans found at positions 916 and 1,535. The $\mathrm{N}$-linked glycans are distributed more evenly between the $\mathrm{NH}_{2}$-terminal and $\mathrm{COOH}$-terminal regions of the vWf subunit. Five of these occur between residues 94 and 811, and seven occur between
+ O-glycans

- O-glycans

$\mathrm{mg} / \mathrm{ml}$ Ristocetin

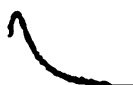

$\mathbf{1}$

0.5
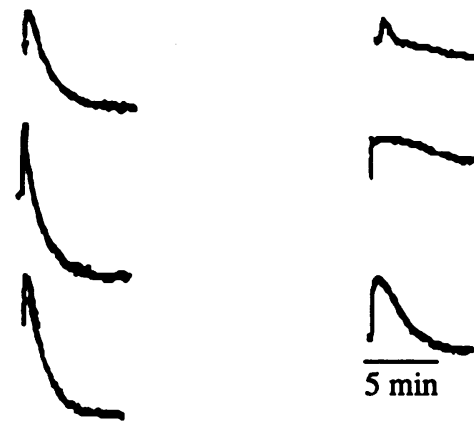

1.0

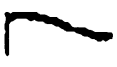

1.5

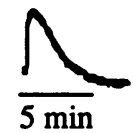

2.2

$\uparrow$

Figure 8. Platelet agglutination by recombinant vWf. $\mathrm{O}^{+}$(left column) or $\mathrm{O}^{-}$( center column) conditioned media were prepared from A-16 cells as described above, and then were concentrated 10 -fold. Aliquots of these concentrated media, containing equivalent amounts of vWf, were stirred at $37^{\circ} \mathrm{C}$ along with $4 \times 10^{7}$ Formalin-fixed human platelets, in a total volume of $300 \mu$, in cuvettes of a dual-channel aggregometer. The change in light transmittance through each sample was monitored after addition of ristocetin at the concentrations noted in the column at the right. The arrows denote the time of addition of ristocetin to the cuvettes, and each tracing runs from left to right.

residues 1,460 and 2,027 (4). Sialic acids and Gal are common constituents of both $\mathrm{N}$-linked and $\mathrm{O}$-linked glycans, and in fact occur on at least some glycans isolated from human vWf ( 35 , 36). The enzymatic removal of these components will therefore introduce alterations in both classes of glycans, and at widely distributed sites. The removal of terminal sialic acids from the carbohydrate of $\mathrm{vWf}$ by treatment with neuraminidase increases sensitivity to proteolysis within the $\mathrm{NH}_{2}$-terminal region, whereas removal of both sialic acids and $\mathrm{Gal}$ by treatment with neuraminidase and $\beta$-galactosidase induces greater sensitivity (37). It has also been demonstrated that enzymatic desialation augments the adhesive interaction of $\mathrm{vWf}$ with the GP lb receptor of washed platelets (38).

We have used the ldl-D system to address the role of $O$ linked carbohydrate modifications to the properties of vWf. In our studies, recombinant $\mathrm{vWf}$ was synthesized by a stably transfected ldl-D isolate, A-16, in apparently equivalent amounts, whether O-linked carbohydrates were present or not. Also, the vWf was able to assemble into dimers and subsequently into multimers when lacking O-linked carbohydrate modifications. The smaller multimeric forms predominated in the vWf secreted by the ldl-D cells. Conversion to the mature subunit (e.g., removal of the propeptide) and the rate and extent of constitutive secretion of the multimers were similarly unaffected by the glycosylation state. Although proteolytic instability in a tissue-culture environment has been implicated as a mechanism in at least one form of vWd, Type IIA (39), such instability was not seen for vWf lacking O-glycans.

The absence of O-linked carbohydrates was without influ- 
ence on the binding between vWf and both collagen type I and heparin but did result in a decreased, not heightened, interaction with platelet GP $1 \mathrm{~b}$ when ristocetin was used as modulator. This effect was evidenced both as a lower overall binding to Formalin-fixed platelets and as a diminished ability of $\mathrm{vWf}$ to agglutinate the platelets at the lower concentrations of ristocetin tested. Because the O-glycan-deficient vWf is stable, and its multimeric distribution appears identical to that of the fully glycosylated recombinant vWf, these observations seem directly attributable to the lack of O-linked glycans. Conversely, the presence of carbohydrates had no apparent influence on the interaction between vWf and GP $1 \mathrm{~b}$ induced by botrocetin.

This observation must be examined with respect to the various differences between ristocetin (a glycopeptide produced by Nocardia lurida) and botrocetin (a glycoprotein factor from the venom of snakes of the genus Bothrops) as cofactors for platelet agglutination by soluble vWf. Ristocetin can cause the precipitation of protein, is more reactive with the larger multimers of vWf than with the smaller multimers, and is confined in reactivity to human platelets and $\mathrm{vWf}(40,41)$. Botrocetin, however, is not known to be a protein-precipitating agent, is reactive with all multimeric forms of $\mathrm{vWf}$, and promotes aggregation with platelets and plasma from many mammalian sources (42-44). Unlike ristocetin, botrocetin is active with vWf from patients with type IIA vWd (41), which may have a lowered affinity for GP lb compared with native vWf (45). The mechanisms of action by which these agents induce vWf-dependent platelet aggregation may differ as well. Ristocetin apparently binds to both the platelet and vWf (40). However, it has been established that botrocetin reacts with the vWf to form a vWf-botrocetin complex, which subsequently interacts with platelet GP $1 \mathrm{~b}(46)$.

The same general region of $\mathrm{vWf}$ (extending from amino acid Val 449-Lys 728) is involved in binding to GP $1 \mathrm{~b}$, whether that binding is induced by ristocetin or botrocetin. Proteolytic fragments of vWf that contain the entire region are reactive with platelets in the presence of either agent $(16,47)$. Among the interesting features of this region (Fig. 1) is the disulfide bond between Cys 509 and Cys 695, which effectively segregates a region having a large proportion of positively charged residues (510-694) from one with few positively charged residues, which is extensively modified by carbohydrate chains, and therefore is expected to carry a strong negative charge (449-509 and 695-728) (48). The importance of the disulfide-loop region and its overall positive charge to the interaction between vWf and GP $1 \mathrm{~b}$ has been shown recently by analyses of amino acid substitutions occurring in type IIB vWf $(49,50)$. Four missense mutations have been reported within the disulfide-loop region; three of these involve the replacement of arginine residues with uncharged residues.

The intrachain disulfide loop may also contain the binding site for botrocetin. The dimeric proteolytic fragment IIIT2, generated by successive digestions of $\mathrm{vWf}$ with protease $\mathrm{V} 8$ and trypsin, which does not contain amino acid residues Leu 521Lys 673 (that is, most of the intrachain disulfide loop), also does not have reactivity with platelets in the presence of botrocetin (23). Recently, it has been suggested that the botrocetinbinding site includes amino acid residues 539-553, 569-583, and 629-643 (51).

With regard to ristocetin-vWf binding, an electrostatic mechanism has been proposed. Ristocetin is cationic and would be expected to interact with a region of the $\mathrm{vWf}$ having a net negative charge (52). It has been suggested that dimeric ristocetin recognizes the amino acid sequence $\mathrm{X}-\mathrm{Pro}-\mathrm{Gly}-\mathrm{X}$. This sequence is found in many proteins that are precipitated by ristocetin (40). Within amino acids Val 449-Lys 728 of vWf there are two of these sequences: Glu-Pro-Gly-Gly (residues 476-479) and Gly-Pro-Gly-Leu (residues 716-719); these occur very near to the O-linked glycosylation sites and to one another. The binding site for GP $1 \mathrm{~b}$ induced by ristocetin apparently involves two noncontiguous regions of $\mathrm{vWf}$, which are drawn together by the Cys 509-Cys 695 disulfide bond (19, 22). Mohri et al. $(19,22)$ have demonstrated that, at high concentrations, either synthetic peptide, corresponding to Cys 474-Pro 488 and Ser 694-Pro 708 of the mature vWf subunit, suppresses the binding between native vWf and platelets in the presence of ristocetin and between asialo-vWf and platelets in the absence of ristocetin. These peptides span the regions thought to bind ristocetin and encompass two of the eight $\mathrm{O}$ linked glycosylation sites of the vWf. It is not yet clear, however, that these noncontiguous regions comprise a GP lbbinding site on vWf, since these same peptides do not inhibit binding to GP $1 \mathrm{~b}$ in the presence of botrocetin (53), and it might be inferred that there is a single GP 1b-binding site on $\mathrm{vWf}$ that is made available in different ways by ristocetin and by botrocetin.

The data we have presented here do not contradict these observations. The O-linked glycans of vWf are clustered near the regions designated as important for binding to platelets in the presence of ristocetin (19), and we have shown an effect of O-glycosylation on ristocetin-induced binding and agglutination. Glycosylation is not absolutely required for the ristocetindependent interaction of vWf with GP $1 \mathrm{~b}$. This is evident, since the synthetic peptides employed by Mohri et al. $(19,22)$ for inhibition of binding were not glycosylated. In addition, Pietu et al. (54) have shown that the Val440-Asn730 fragment of vWf cDNA expressed in Escherichia coli can bind to washed platelets in the presence of $1 \mathrm{mg} / \mathrm{ml}$ ristocetin and that a synthetic peptide corresponding to amino acids $692-708$ of $\mathrm{vWf}$ can inhibit this interaction. Our data suggest only that the Oglycans of $v W f$ have a positive influence upon the interaction with GP $1 \mathrm{~b}$ induced by ristocetin, whereas their absence diminishes the interaction. Desialation of $\mathrm{vWf}$ permits a spontaneous interaction with platelets and, presumably, desialation of the O-glycans contributes to this effect. However, our data suggest that the absence of entire O-glycans might significantly alter the local conformation of the protein so that it is no longer able to interact properly with either ristocetin or GP $1 \mathrm{~b}$, or both. The data indicating that platelet binding in the presence of botrocetin is not affected by the glycosylation state of $\mathrm{vWf}$ also do not contradict prior observations, since the disulfide-loop region of $\mathrm{vWf}$, required for botrocetin reactivity, is not glycosylated.

At present, there is no clear association between the extent of carbohydrate modification of $\mathrm{vWf}$, and $\mathrm{vWd}$, which might be due to any of a diverse number of causes. In type I vWd, there is an overall decrease in the amount of apparently normal $v W f$ protein present in the plasma, although the entire spectrum of multimers is represented (2). In type IIA vWd there is either proteolytic instability of the vWf multimers, especially the largest multimers, in the plasma (39) or a defect in vWf secretion ( 55 ). However, bleeding abnormalities might also be occasioned by an aberration in the binding characteristics of an apparently quantitatively and structurally normal $\mathrm{vWf}$ protein. 
For instance, in a variant form of $\mathrm{vWd}$ the bleeding disorder arises from a decreased binding between $\mathrm{vWf}$ and Factor VIIIC, attributable to a defect in the vWf protein $(56,57)$. A similar mechanism was recently implicated in type IIB vWd, where the decrease in both circulating platelets and the larger vWf multimers from plasma is attributable to spontaneous binding between soluble vWf and platelets $(18,58)$. It has been reported that type IIA vWf may have reduced affinity for GP $1 \mathrm{~b}$ as well (45). It might be expected that any defect in $\mathrm{vWf}$ that reduced the extent of the interaction with GP $1 \mathrm{~b}$ might also induce a clinically significant bleeding disorder. We have shown here that a lack of $\mathrm{O}$-linked carbohydrate modifications on vWf may be one such defect that hinders appropriate platelet agglutination.

It is not known at present whether the effect we have described is a cumulative response to the loss of several O-linked carbohydrates or whether it could result, for instance, from a point mutation causing the loss of a single key O-linked carbohydrate attachment site. The presence of the eight O-linked carbohydrate modifications in a cluster around the ristocetindependent GP 1b-binding site might help to maintain an optimal conformation of this region of $\mathrm{vWf}$ for appropriate binding to the platelet surface, and only the loss of most or all of these might be sufficient to produce a phenotypically altered vWf protein. Alternatively, if O-glycosylations at one or a few critical positions participate directly in the vWf-GP lb-binding reaction, the loss of even a single $\mathrm{O}$-linked carbohydrate might result in a dysfunctional vWf protein. We are currently undertaking experiments to differentiate between these possibilities.

\section{Acknowledgments}

The authors would like to thank Dr. M. Krieger for providing ldl-D cells, Dr. M. Read for the gift of botrocetin, Dr. N. Sarva for the p-198 plasmid, Drs. D. Kaplan and T. Roberts for the pHSV-neo plasmid, Dr. Z. Ruggeri for the monoclonal antibody 2.2.9, and Dr. A. Ware for use of the aggregometer.

This research was supported by National Institutes of Health grants 31311 and 41222. J. A. Carew is a Judith Graham Pool Postdoctoral Fellow of the National Hemophilia Foundation. J. H. Stoddart is supported by National Institutes of Health Postdoctoral Fellowship HL08270 .

\section{References}

1. Girma, J. P., D. Meyer, C. L. Verweij, H. Pannekoek, and J. J. Sixma. 1987. Structure-function relationship of human von Willebrand factor. Blood. 70:605611.

2. Ruggeri, Z. M., and T. S. Zimmerman. 1987. von Willebrand factor and von Willebrand disease. Blood. 70:895-904.

3. Wagner, D. D., and V. J. Marder. 1984. Biosynthesis of von Willebrand protein by human endothelial cells. Processing steps and their intracellular localization. J. Cell Biol. 99:2123-2130.

4. Titani, K., S. Kumar, K. Takio, L. H. Ericsson, R. D. Wade, K. Ashida, K. A. Walsh, M. W. Chopek, J. E. Sadler, and K. Fujkawa. 1986. Amino acid sequence of human von Willebrand factor. Biochemistry. 25:3171-3184.

5. Carew, J. A., P. J. Browning, and D. C. Lynch. 1990. Sulfation of von Willebrand factor. Blood. 76: 2530-2539.

6. Lynch, D. C., T. S. Zimmerman, E. P. Kirby, and D. M. Livingston. 1983. Subunit composition of oligomeric human von Willebrand factor. J. Biol. Chem. 258:12757-12760.

7. Wagner, D. D., and V. J. Marder. 1983. Biosynthesis of von Willebrand protein by human endothelial cells: identification of a large precursor polypeptide chain. J. Biol. Chem. 258:2065-2067.

8. McCarroll, D. R., E. G. Levin, and R. R. Montgomery. 1985. Endothelial cell synthesis of von Willebrand antigen II, von Willebrand factor, and von Willebrand factor/von Willebrand antigen II complex. J. Clin. Invest. 75:1089-1095.

9. Verweij, C. L., M. Hart, and H. Pannekoek. 1987. Expression of variant von Willebrand factor (vWf) cDNA in heterologous cells: requirement of the pro-polypeptide in vWF multimer formation. EMBO (Eur. Mol. Biol. Organ.) J. 6:2885-2890.

10. Wise, R. J., D. D. Pittman, R. I. Handin, R. J. Kaufman, and S. H. Orkin. 1988. The propeptide of von Willebrand factor independently mediates the assembly of von Willebrand multimers. Cell. 52:229-236.

11. Fay, P. J., Y. Kawai, D. D. Wagner, D. Ginsburg, D. Bonthron, B. M. Ohlsson-Wilhelm, S. I. Chavin, G. N. Abraham, R. I. Handin, S. H. Orkin, et al. 1986. Propolypeptide of von Willebrand factor circulates in blood and is identical to von Willebrand antigen II. Science (Wash. DC). 232:995-998.

12. Wagner, D. D., P. J. Fay, L. A. Sporn, S. Smiti, S. O. Lawrence, and V. J. Marder. 1987. Divergent fates of von Willebrand factor and its propolypeptide (von Willebrand antigen II) after secretion from endothelial cells. Proc. Natl. Acad. Sci. USA. 84:1955-1959.

13. Foster, P. A., C. A. Fulcher, T. Marti, K. Titani, and T. S. Zimmerman. 1987. A major factor VIII binding domain resides within the amino-terminal 272 amino acid residues of von Willebrand factor. J. Biol. Chem. 262:8443-8446.

14. Fujimura, Y., K. Titani, L. Z. Holland, J. R. Roberts, P. Kostel, Z. M. Ruggeri, and T. S. Zimmerman. 1987. A heparin-binding domain of human von Willebrand factor. J. Biol. Chem. 262:1734-1739.

15. Pareti, F. I., Y. Fujimura, J. A. Dent, L. Z. Holland, T. S. Zimmerman, and Z. M. Ruggeri. 1986. Isolation and characterization of a collagen binding domain in human von Willebrand factor. J. Biol. Chem. 261:15310-15315.

16. Fujimura, Y., K. Titani, L. Z. Holland, S. R. Russell, H. H. Elder, Z. M. Ruggeri, and T. S. Zimmerman. 1986. von Willebrand factor: a reduced and alkylated 53/48-kDa fragment beginning at amino acid residue 449 contains the domain interacting with platelet glycoprotein Ib. J. Biol. Chem. 261:381-385.

17. Jenkins, C. S. P., D. R. Phillips, K. J. Clemetson, D. Meyer, M.-J. Larieu, and E. F. Luscher. 1976. Platelet membrane glycoproteins implicated in ristocetin-induced aggregation. Studies of the proteins on platelets from patients with Bernard-Soulier syndrome and von Willebrand disease. J. Clin. Invest. 57:112124.

18. Ruggeri, Z. M., F. I. Pareti, P. M. Mannucci, N. Ciavarella, and T. S. Zimmerman. 1980. Heightened interaction between platelets and factor VIII/ von Willebrand factor in a new subtype of von Willebrand's disease. $N$. Engl. J. Med. 302:1047-1051.

19. Mohri, H., Y. Fujimura, M. Shima, A. Yoshioka, R. A. Houghten, Z. M. Ruggeri, and T. S. Zimmerman. 1988. Structure of the von Willebrand factor domain interacting with glycoprotein Ib. J. Biol. Chem. 263:17901-17904.

20. Marti, T., S. J. Rosselet, K. Titani, and K. A. Walsh. 1987. Identification of disulfide-bridged substructures within human von Willebrand factor. Biochemistry. 26:8099-8109.

21. Girma, J. P., Y. Takahashi, A. Yoshioka, J. Diaz, and D. Meyer. 1990. Ristocetin and botrocetin involve two distinct domains of von Willebrand factor for binding to platelet membrane glycoprotein Ib. Thromb. Haemostasis. 64:326-335.

22. Mohri, H., A. Yoshioka, T. S. Zimmerman, and Z. M. Ruggeri. 1989. Isolation of the von Willebrand factor domain interacting with platelet glycoprotein Ib, heparin, and collagen and characterization of its three distinct functional sites. J. Biol. Chem. 264:17361-17367.

23. Fujimura, Y., Y. Usami, K. Titani, K. Niinomi, K. Nishio, T. Takase, A Yoshioka, and H. Fukui. 1991. Studies on anti-von Willebrand factor (vWf) monoclonal antibody NMC-4, which inhibits both ristocetin and botrocetin-induced vWf binding to platelet glycoprotein Ib. Blood. 77:113-120.

24. Southern, P., and P. Berg. 1982. Transformation of mammalian cells to antibiotic resistance with a bacterial gene under control of the SV40 early promoter region. J. Mol. Appl. Genet. 1:327-341.

25. Bockenstedt, P., J. M. Greenberg, and R. I. Handin. 1986. Structural basis of von Willebrand factor binding to platelet glycoprotein Ib and collagen. J. Clin. Invest. 77:743-749.

26. Kingsley, D. M., K. F. Kozarsky, L. Hobbie, and M. Krieger. 1986. Reversible defects in O-linked glycosylation and LDL receptor expression in a UDP. Gal/UDP-GalNAc 4-epimerase deficient mutant. Cell. 44:749-759.

27. Kornfeld, R., and S. Kornfeld. 1980. Structure of glycoproteins and their oligosaccharide units. In The Biochemistry of Glycoproteins and Proteoglycans. W. J. Lennarz, editor. Plenum Press, New York. 1-32.

28. Sporn, L. A., V. J. Marder, and D. D. Wagner. 1986. Inducible secretion of large, biologically potent von Willebrand factor multimers. Cell. 46:185-190.

29. Kozarsky, K. F., S. M. Call, S. K. Dower, and M. Krieger. 1988. Abnormal intracellular sorting of O-linked carbohydrate-deficient interleukin-2 receptors. Mol. Cell. Biol. 3357-3363.

30. Reddy, P., I. Caras, and M. Krieger. 1989. Effects of O-linked glycosylation on the cell surface expression and stability of decay-accelerating factor, a glycophospholipid-anchored membrane protein. J. Biol. Chem. 264:1732917336.

31. Shogren, R., T. A. Gerken, and N. Jentoft. 1989. Role of glycosylation on the conformation and chain dimensions of O-linked glycoproteins: light-scattering studies of ovine submaxillary mucin. Biochemistry. 28:5525-5536.

32. Oh-eda, M., M. Hasegawa, K. Hattori, H. Kuboniwa, T. Kojima, T. Orita, 
K. Tomonou, T. Yamazaki, and N. Ochi. 1990. O-linked sugar chain of human granulocyte colony-stimulating factor protects it against polymerization and denaturation allowing it to retain its biological activity. J. Biol. Chem. 265:1143211435.

33. Zanni, E. E., A. Kouvatsi, M. Hadzopoulou-Cladaras, M. Krieger, and V. I. Zannis. 1989. Expression of apoE gene in Chinese hamster cells with a reversible defect in O-glycosylation. J. Biol. Chem. 264:9137-9140.

34. Matzuk, M. M., M. Krieger, C. L. Corless, and I. Boime. 1987. Effects of preventing O-glycosylation on the secretion of human chorionic gonadotropin in Chinese hamster ovary cells. Proc. Natl. Acad. Sci. USA. 84:6354-6358.

35. Debeire, P., J. Montreuil, B. Samor, C. Mazurier, M. Goudemand, H. Van Halbeek, and J. F. G. Vliegenthart. 1983. Structure determination of the major asparagine-linked sugar chain of human factor VIII-von Willebrand factor. FEBS (Fed. Eur. Biochem. Soc.) Lett. 151:22-26.

36. Samor, B., J. C. Michalski, C. Mazurier, M. Goudemand, P. De Waard, J. F. G. Vliegenthart, G. Strecker, and J. Montreuil. 1989. Primary structure of the major O-glycosidically linked carbohydrate unit of human von Willebrand factor. Glycocon. J. 6:263-270.

37. Berkowitz, S. D., and A. B. Federici. 1988. Sialic acid prevents loss of large von Willebrand factor multimers by protecting against amino-terminal proteolytic cleavage. Blood. 72:1790-1798.

38. De Marco, L., and S. S. Shapiro. 1981. Properties of human asialo-factor VIII: a ristocetin-independent platelet-aggregating agent. J. Clin. Invest. 68:321328.

39. Levene, R. B., F. M. Booyse, J. Chediak, T. S. Zimmerman, D. M. Livingston, and D. C. Lynch. 1988. Expression of abnormal von Willebrand factor by endothelial cells from a patient with type IIA von Willebrand disease. Proc. Natl. Acad. Sci. USA. 84:6550-6554.

40. Scott, J. P., R. R. Montgomery, and G. S. Retzinger. 1991. Dimeric ristocetin flocculates proteins, binds to platelets, and mediates von Willebrand factor-dependent agglutination of platelets. J. Biol. Chem. 266:8149-8155.

41. Brinkhous, K. M., M. S. Read, W. A. Fricke, and R. H. Wagner. 1983. Botrocetin (venom coagglutinin): reaction with a broad spectrum of multimeric forms of factor VIII macromolecular complex. Proc. Natl. Acad. Sci. USA. 80:1463-1466.

42. Read, M. S., 1978. Venom coagglutinin: an activator of platelet aggregation dependent on von Willebrand factor. Proc. Natl. Acad. Sci. USA. 75:45144518.

43. Andrews, R. K., W. J. Booth, J. J. Gorman, P. A. Castaldi, and M. C. Berndt. 1990. Purification of botrocetin from Bothrops jararaca venom. Analysis of the botrocetin-mediated interaction between von Willebrand factor and the human platelet membrane glycoprotein Ib-IX complex. Biochemistry. 28:83178326.

44. Fujimura, Y., K. Titani, Y. Usami, M. Suzuki, R. Oyama, T. Natsui, H. Fukui, M. Sugimoto, and Z. M. Ruggeri. 1991. Isolation and chemical characterization of two structurally and functionally distinct forms of botrocetin, the platelet coagglutinin isolated from the venom of Bothrops jararaca. Biochemistry. 30:1957-1964.

45. De Marco, L., M. Mazzucato, D. De Roia, A. Casonato, A. B. Federici, A Girolami, and Z. M. Ruggeri. 1990. Distinct abnormalities in the interaction of purified Types IIA and IIB von Willebrand factor with the two platelet binding sites, glycoprotein complexes Ib-IX and IIb-IIla. J. Clin. Invest. 86:785-792.

46. Read, M. S., S. V. Smith, M. A. Lamb, and K. M. Brinkhous. 1989. Role of botrocetin in platelet agglutination: formation of an activated complex of botrocetin and von Willebrand factor. Blood. 74:1031-1035.

47. Fujimura, Y., L. Z. Holland, Z. M. Ruggeri, and T. S. Zimmerman. 1987. The von Willebrand factor domain mediating botrocetin-induced binding to glycoprotein Ib lies between Val 449 and Lys 728. Blood. 70:985-988.

48. Andrews, R. K., J. J. Gorman, W. J. Booth, G. L. Corino, P. A. Castaldi, and M. C. Berndt. 1989. Cross-Linking of a monomeric 39/34-kDa dispase fragment of von Willebrand factor (Leu-480/Val-481-Gly 718) to the N-terminal region of the alpha-chain of membrane glycoprotein Ib on intact platelets with bis(sulfosuccinimidyl) suberate. Biochemistry. 28:8326-8336.

49. Cooney, K. A., W. C. Nichols, M. E. Bruck, W. F. Bahou, A. D. Shapiro, E. J. W. Bowie, H. R. Gralnick, and D. Ginsburg. 1991. The molecular defect in Type IIB von Willebrand disease. Identification of four potential missense mutations within the putative GP $1 \mathrm{~b}$ binding domain. J. Clin. Invest. 87:1227-1233.

50. Randi, A. M., I. Rabinowitz, D. J. Mancuso, P. M. Mannucci and J. E. Sadler. 1991. Molecular basis of von Willebrand disease Type IIB. Candidate mutations cluster in one disulfide loop between proposed platelet glycoprotein Ib binding sequences. J. Clin. Invest. 87:1220-1226.

51. Ruggeri, Z. M. 1991. Structural regulation of von Willebrand factor interaction with platelets and the subendothelium. Thromb. Haemostasis. 65:746

52. Howard, M. A., and B. G. Firkin. 1971. Ristocetin-A new tool in the investigation of platelet aggregation. Thromb. Haemostasis. 26:362-369.

53. Girma, J. P., Y. Takahashi, A. Yoshioka, J. Diaz, and D. Meyer. 1990. Ristocetin and botrocetin involve two distinct domains of von Willebrand factor for binding to platelet membrane glycoprotein Ib. Thromb. Haemostasis. 64:326-335.

54. Pietu, G., P. Meullen, G. Cherel, J. Diaz, D. Baruch, M. Courtney, and D. Meyer. 1989. Production in Escherichia coli of a biologically active subfragment of von Willebrand factor corresponding to the platelet glycoprotein Ib, collagen and heparin binding domains. Biochem. Biophys. Res. Commun. 164:13391347.

55. Lyons, S. E., M. E. Bruck, E. J. W. Bowie, and D. Ginsburg. 1992. Impaired intracellular transport produced by a subset of Type IIA von Willebrand disease mutations. J. Biol. Chem. 267:4424-4430.

56. Mazurier, C., J. Dieval, S. Jorieux, J. Delobel, and M. Goudemand. 1990. A new von Willebrand factor (vWf) defect in a patient with Factor VIII (FVIII) deficiency but with normal levels and multimeric patterns of both plasma and platelet vWf. Characterization of abnormal vWf/FVIII interaction. Blood. 75:20-26.

57. Nishino, M., J. P. Girma, C. Rothschild, E. Fressinaud, and D. Meyer 1989. New variant of von Willebrand disease with defective binding to factor VIII. Blood. 74:1591-1599.

58. de Groot, P. G., A. B. Federici, H. C. de Boer, P. D'Alessio, P. M. Mannucci, and J. J. Sixma. 1989. von Willebrand factor synthesized by endothelia cells from a patient with Type IIB von Willebrand disease supports platelet adhesion normally but has an increased affinity for platelets. Proc. Natl. Acad. Sci. USA. 86:3793-3797. 